\title{
Basic features of the predictive tools of early warning systems for water-related natural hazards: examples for shallow landslides
}

\author{
Roberto Greco $^{1}$ and Luca Pagano ${ }^{2}$ \\ ${ }^{1}$ Dipartimento di Ingegneria Civile Design Edilizia e Ambiente, Universitá degli Studi della Campania "Luigi Vanvitelli", \\ Via Roma 9, 81031 Aversa (CE), Italy \\ ${ }^{2}$ Dipartimento di Ingegneria Civile Edile e Ambientale, Universitá degli Studi di Napoli Federico II, \\ Via Claudio 21, 80125 Napoli, Italy
}

Correspondence to: Luca Pagano (luca.pagano@unina.it)

Received: 17 July 2017 - Discussion started: 26 July 2017

Revised: 17 November 2017 - Accepted: 23 November 2017 - Published: 8 December 2017

\begin{abstract}
To manage natural risks, an increasing effort is being put in the development of early warning systems (EWS), namely, approaches facing catastrophic phenomena by timely forecasting and alarm spreading throughout exposed population. Research efforts aimed at the development and implementation of effective EWS should especially concern the definition and calibration of the interpretative model. This paper analyses the main features characterizing predictive models working in EWS by discussing their aims and their features in terms of model accuracy, evolutionary stage of the phenomenon at which the prediction is carried out and model architecture. Original classification criteria based on these features are developed throughout the paper and shown in their practical implementation through examples of flowlike landslides and earth flows, both of which are characterized by rapid evolution and quite representative of many applications of EWS.
\end{abstract}

\section{Introduction}

Natural hazards that turn into catastrophes have been widespread in Italy in the recent past as well as in the last few centuries. Seismic and volcanic phenomena have sporadically affected large areas, while rainfall-induced landslides, floods and snow avalanches have frequently hit sites spread all over the territory. Structural mitigation approaches are inapplicable throughout the entire at-risk territory and would only be planned for areas relevant from a socioeconomic point of view.
Hence, to manage natural risks, an increasing effort is being made in the development of nonstructural approaches, based on timely forecasts of the catastrophic phenomena from precursors or indicators in order to forewarn the exposed areas (early warning) and temporarily eliminate or at least reduce the exposure of people, preventing or limiting deaths (Basher, 2006). The increasing importance of early warning systems (EWS) is testified by the fact that they are among the priorities adopted by the United Nations International Strategy for Disaster Reduction (ISDR) (UN-ISDR, 2005, 2006).

EWS indeed present undeniable advantages, among which are their fast, simple and low-cost implementation and environmental friendliness. Focusing on water-related hazards, significant examples of operational EWS are currently found in the field of floods, landslides, snow avalanches and earth fill failures. A recent review of EWS operating in Europe for water-related hazards can be found in Alfieri et al. (2012).

As will be described in detail in the following paper, the architecture of an EWS is strictly related to the time needed for the deployment of the mitigation measures compared to the time of evolution of the hazardous event. In this respect, EWS for floods present quite different features if they are established along large or small rivers. In the first case, rainfall measurements or predictions are supplemented with river stage measurements in upstream sections (e.g., Rabuffetti and Barbero, 2005), and flood routing models can be run as a cascade of hydrological models (e.g., Cranston and Tavendale, 2012). The lead time of prediction, which depends on the length of the river and on the extension of its catchment, 
can extend up to several days or weeks. In the case of small streams, the time lapse between rainfall and peak discharge may be so short that weather nowcasting is needed for the warning to be launched in time (e.g., Alfieri and Thielen, 2015; de Saint-Aubin et al., 2016).

So far, most of the EWS dealing with rainfall-induced landslides are based on rainfall measurements, sometimes supported by weather forecasts (e.g., Keefer et al., 1987; Ponziani et al., 2012), but are rarely integrated into monitoring of certain soil variables (e.g., Ortigao and Justi, 2004; Chleborad et al., 2008; Baum and Godt, 2010). Rainfall is often interpreted merely statistically, with an empirical quantification of rainfall thresholds for landslide initiation (e.g., Sirangelo and Versace, 1996; Sirangelo and Braca, 2004; Guzzetti et al., 2007, 2008; Capparelli and Tiranti, 2010; Tiranti and Rabuffetti, 2010; Martelloni et al., 2012; Segoni et al., 2014; Tiranti et al., 2014; Piciullo et al., 2017). In rare cases, physically based approaches are adopted for the interpretation of the effects of rainfall history. The few examples of inclusion of slope infiltration and stability modeling in the assessment of the safety conditions are mostly still at a prototypal stage (e.g., Schmidt et al., 2008; Capparelli and Versace, 2011; Ponziani et al., 2012; Eichenberger et al., 2013; Pumo et al., 2016).

EWS operating for snow avalanches monitor snow accumulation and the melting processes, with the former based essentially on interpreting precipitation and air temperature records and the latter on air (or snow) temperature (e.g., Liu et al., 2009).

Even in the field of man-made systems, early warning is assuming a prominent role in the assessment of the risk associated with failure. For instance, in the field of earth fill dams, with regard to all possible collapse mechanisms, i.e., slope instability and internal erosion phenomena, or even earthquake-induced effects, risk mitigation is de facto based on EWS (e.g., Pagano and Sica, 2013; Ma and Chi, 2016). The monitoring system commonly installed to characterize the behavior of these structures sporadically, carried out in terms of displacements, porewater pressure, seepage flows and accelerations, is pointed towards a continuous checking of dam safety conditions, aimed at evacuating downstream settlements in case of predicted collapse.

The literature indicates that common elements, which typically characterize an EWS (e.g., Intrieri et al., 2012, 2013; Calvello and Piciullo, 2016), are as follows:

1. A field monitoring system records physical quantities related to the phenomenon at hand and transmits them to a collection-elaboration center. Measured variables may conveniently be distinguished into two categories: cause variables, leading to the initiation of the phenomenon, and effect variables that, affected by the formers, characterize the phenomenon itself during its evolution and at its triggering, allowing us to also recognize its intensity.
2. A predictive model mathematically formalizes the relationships linking cause and effect variables, allowing us to catch the evolutionary stage of the phenomenon and assess system safety conditions.

3. Thresholds for the variables, related to safety conditions of the system, correspond to different alert levels, with the highest one activating the spread of the alarm message, aimed at eliminating people exposure.

4. Different actions are related to each alert level defined in point 3.

Research efforts aimed at the development and implementation of effective EWS should concern, above all, the definition, calibration and validation of the predictive model (Michoud et al., 2013). The model should be as accurate as possible and, at the same time, capable of rapidly using the monitored quantities to assess the system safety conditions. In many applications dealing with rapidly evolving natural hazards, a real-time working system is in fact required in order to maximize the lead time available to reduce or eliminate the exposure of people to the hazard.

The aim of this paper is to address the main features of predictive models for water-related natural hazards. The proposed frame is quite general and applicable to other types of natural hazards, and thus references will be briefly made throughout this paper to applications apart from water-related hazards. In particular, based on the precise definition of the aims of the EWS, this work addresses the importance of identifying the evolutionary stage of the catastrophic event at which the prediction should be implemented, so as to maximize its effectiveness. For the first time the evolutionary stage at which the predictive model is implemented is considered to be one of its features, along with the other traditional approach distinguishing between empirical and physically based models.

In principle, any predictive model might be related to any spatial scale, which is thus not considered to be a valid classification element for EWS models. Rather, the classification criteria proposed throughout this paper may be referred to all scales. The choice to show all specific examples related to rainfall-induced landslides at a slope scale is not made to reduce generality of the proposed criteria but rather as an attempt to select an application field whose representativeness poses challenges extendible to other natural phenomena.

\section{Prediction uncertainty and the minimization of the costs of missing and false alarms of an EWS}

Whatever the predictive model adopted, it will never be capable of providing certainty about the occurrence of a catastrophic event. A model yields variables systematically affected by a given uncertainty degree due to the following possible causes: 
- incompleteness of information about the physical system that could cause catastrophes;

- various error types associated with the measurements provided by the monitoring system;

- unavoidable simplifications of reality always introduced when building the predictive model;

- randomness of some of the processes involved in the genesis of the catastrophic event.

It is obvious that the uncertainties of the predicted variables related to the physical system affect the assumption of different alert stages. With reference to the last stage, the EWS may issue an alarm, but no dangerous phenomenon occurs (false alarm) or, conversely, that a dangerous phenomenon takes place without any issued alarm (missing alarm). Both false and missing alarms are costly to the community served by the EWS. A lower uncertainty degree in the prediction is required to minimize their number and, consequently, costs during the system operation. Efficiency of the EWS is therefore considered with respect to its economic value for the community rather than merely to the provided safety performance. In this sense, alarm activation has to account for the uncertainties associated with overcoming each alert threshold, so as to minimize false and missing alarms and related costs.

Decisional rules regarding actions associated with each alert threshold should be based not only on the mere quantification of thresholds themselves but also on criteria defining the sensitivity of the EWS, intended to set the activation of the system at some probability of a given threshold to be exceeded.

The most suitable strategy to quantify such probability of threshold exceedance cannot be generalized. It is in fact strongly affected by the following particularities characterizing the EWS at hand:

- the uncertainty of the prediction, which may be reduced by increasing the initial investment (by preliminary acquiring more information about physical system features, implementing a more reliable monitoring system with higher spatial and temporal resolution and elaborating a more sophisticated and accurate predictive model);

- the costs suffered by the community in case of false alarms, in turn depending also on the kind of actions planned in case of threshold exceedance;

- the costs resulting from a missing alarm, depending on both the event (type and intensity) and resilience of the exposed goods (related to their nature as well as to socioeconomic aspects).

In setting up the EWS sensitivity, it should be taken into account that too many false alarms would discredit the system,

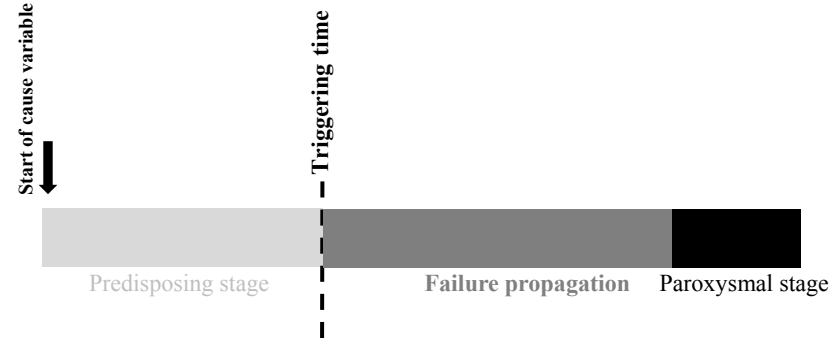

Time needed to eliminate people exposure

Figure 1. Evolutionary stages of a collapse mechanism.

implying that, over time, the served community would contribute less to carrying out all the required actions after alerts. In short, the sensitivity has to be calibrated on the basis of a cost-benefit analysis, which can be properly carried out only if the uncertainty of model predictions can be estimated after an adequate period of monitoring of the physical system.

\section{Evolutionary stages of a natural hazard: when should the model do the prediction?}

In order to generalize a typical architecture for the predictive model, it is useful to account for a conventional sequence of stages describing the evolution of a natural phenomenon resulting in a catastrophe (Fig. 1):

a. the predisposing stage, in which the cause variables are subject to changes that induce significant modifications of effect variables;

b. the triggering and propagation stage, in which the failure occurs locally (triggering time) and propagates from point to point until it involves the entire physical system;

c. the paroxysmal stage, in which the physical system collapses and the kinematics of the system continues, eventually hitting the exposed goods.

The duration of each stage may greatly vary, depending on both the kind of phenomenon and on the features of the physical system involved.

When an earthquake hits structures located at a given site "S", the predisposing stage (a) is determined by the occurrence of the seismic event at the epicenter and is indicated by the first arrival of the seismic waves at the seismometers nearest to the epicenter. The triggering and propagation stage (b) is determined by acceleration values exceeding the threshold for first local damages to structural elements and is monitored by seismic stations located at "S". The paroxysmal stage (c) consists of the collapse of parts of the struc- 
tures. For this specific example, the duration of stages (a) and (b) is several tens of seconds, while the duration of stage (c) depends on the system considered, spanning from seconds for systems like buildings, rock slopes, gas conduits, etc., to hours or even days for natural earth slopes and dams, and, in general, system collapse is determined by a slow redistribution or propagation of earthquake-induced effects.

In a rainfall-induced landslide, the predisposing stage (a) is determined by the sequence of rainfall events and by the hydrological processes leading to an increase of porewater pressure and worsening slope stability conditions (e.g., Bogaard and Greco, 2015). The triggering and propagation stage (b) spans from the first local slope failure until the formation of a slip surface. The paroxysmal stage (c) is the sliding of the mobilized soil mass downhill along the slip surface. In this second example, the duration of each stage is strongly related to the geomorphology of the specific slope and to the type of landslide (Varnes, 1978) and may vary from minutes (e.g., flow slides in slopes covered with shallow coarse-grained soils) to even years (e.g., some earth flows in slopes of fine-grained soils).

In a snow avalanche, the predisposing stage (a) is determined by snow accumulation and temperature increments; the triggering and propagation stage (b) starts when local failures take place within the snow aggregate and ends with a slip surface formation. The paroxysmal stage (c) starts when the mass slides downhill. In this example, the duration of stage (a) may be of hours or days, depending on the evolution of atmospheric variables, while the duration of stage (b) is undetectable, and the paroxysmal stage lasts only few seconds.

For the case of an overflow in a river, the predisposing stage (a) is a sequence of precipitation events within the watershed, causing a progressive increase of the water level along the river course; in this case, the triggering and propagation stage (b) and the paroxysmal stage (c) are hardly distinguishable from each other. In fact, both stages start when the first local overflow takes place, and both develop with the flood propagating around the river. The stage duration depends on the extension and geomorphology of the watershed. The entire phenomenon may last tens of minutes (e.g., flash floods in small streams with relatively small catchment) to several days (e.g., large rivers with large watershed).

It is also important to highlight that for most phenomena the triggering event has to be considered random and, as such, time and location of its occurrence can be predicted only with a probabilistic approach. In contrast, the predisposing stage can be usually described with physical laws, so that its spatial and temporal evolution can be predicted deterministically by mathematical models.

For instance, the strategies followed for early warning with respect to snow avalanches (e.g., Bakkeoi, 1986) neglect the detection of any possible triggering factor. These may be internal in the physical system (related to some peculiar morphologies favoring the susceptibility to local failures) or ex- ternal (e.g., a skier path cutting transversally the snow layer slope or a rock mass falling onto the layer). The randomness of such triggering factors makes them undetectable and useless for early warning purposes. However, it should be noted that these factors may become effective only if a predisposing state takes place in terms of snow layer thickness and temperature. This leads us to define the different alert levels on the basis of these two variables, for which experimental quantification is easy and reliable. Consequently, the warning does not deal with exactly identifying when, where and what specific triggering factor might generate an avalanche.

In general, early warning prediction can be carried out during any of the above-defined evolutionary stages. The choice of the particular stage should obviously consider that elapsed times needed to predict the event, sound the alarm and reduce people and goods exposure must not exceed the time after which the destructive event occurs. However, the limited time available between prediction and event should impact which kind of actions could be reasonably carried out. So, only in some cases will it be possible to consider the opportunity to evacuate all buildings of an entire neighborhood or forbid access to all exposed streets. In some cases, the short available time only allows some quick actions, such as the interruption of dangerous supplied services (gas and electricity) or closure of important, highly exposed infrastructures, such as railways or highways.

The first step in the development of the predictive tool is hence the detailed study of the mechanisms that control the evolution of the phenomenon at hand and identification of the most suitable phenomenon stage for the assessment of safety conditions. For some problems, the choice will necessarily be one specific stage, while for others the choice may be multiple stages. For instance, the slow kinematics of landslides in fine-grained soils allows us to use the predictive tool in any of the three above-defined stages, while the rapid kinematics of rainfall-induced landslides in coarse-grained soils prevents us from considering the paroxysmal stage.

\section{The architecture of the predictive model}

The second step of the development of the predictive tool is choosing the predictive model. Promptness and reliability are mandatory requirements of the prediction. The promptness is usually obtained by introducing model simplifications, which should, however, not imply excessive accuracy losses because they would increase uncertainties and, consequently, false and missing alarms. An increase of model complexity usually corresponds with a reduction in the observational scale of the phenomenon. Complex models can only be applied to slope scale problems, while, increasing the observational scale from local to regional, progressive simplifications have to be introduced in the model and less ambitious goals have to be set in terms of reliability. 
The wide variety of applications for EWS makes it difficult to generalize criteria to guide the choice of the predictive model. It is only possible to refer to some classification criteria, those that aim to clarify the philosophy of the chosen approach and what components are required for best implementation.

The first classification criterion distinguishes between empirical and physically based models. Empirical models extract relationships among cause and effect variables from available monitoring data taken over a prolonged time interval. Once the empirical relationships were set up, they typically do not take into account the physics governing the phenomenon. Their reliability essentially depends on the amount, accuracy and representativeness of the available data set.

In contrast, physically based models relate cause and effect variables through mathematical relationships derived straightforwardly from the physical principles governing the considered phenomenon. The mathematical description of the model typically involves the assumption of simplifications that could strongly affect the accuracy of the prediction.

These two categories may also be used contextually to set up predictive tools consisting of physically based and empirical steps.

The second criterion of classification refers essentially to physically based models and is strictly related to the need for a rapid prediction. It distinguishes between online and offline predictions. The former consist of the real-time solution of the model equations, updated continuously over time with changes in boundary conditions indicated by field monitoring. The latter define simple mathematical equations or charts linking cause and effect variables by solving the governing equations preliminarily for a number of possible scenarios in terms of initial and boundary conditions (e.g, Pagano and Sica, 2013). These simple mathematical equations or abaci represent the predictive tools adopted to rapidly interpret the data from field monitoring.

Strictly related to the selection of the model is the design of the monitoring system. It has to be consistent with all the choices made about the previously illustrated points. The considered specific stage of phenomenon evolution, as well as the choice of predictive model, unequivocally identifies the physical variables to be monitored, their location and the number of measurement points.

In the following sections, the different features highlighted above will guide the illustration of some application cases developed in the field of rainfall-induced flow-like landslides.

\section{Examples of setup and calibration of the predictive model for early warning}

In Italy the destructive potential of rainfall-induced rapid flow slides and debris flows is unfortunately well known. The significance of the problem in terms of number of events and

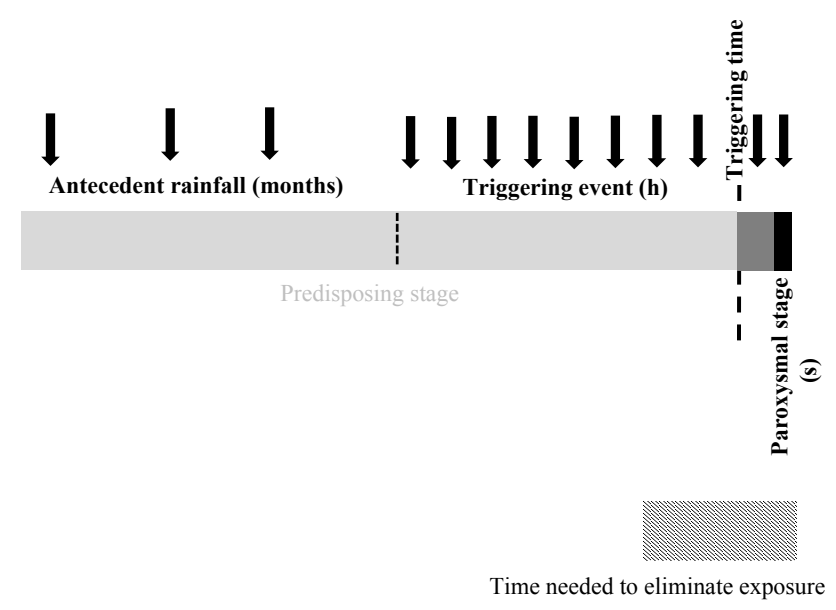

Figure 2. Evolutionary stages of collapse mechanism in rainfallinduced landslides featured by rapid kinematic.

victims becomes clear by merely referring to the disasters that occurred over the last few years in Campania (Cascini and Ferlisi, 2003; Calcaterra et al., 2004; Pagano et al., 2010; Santo et al., 2012), Piedmont (Villar Pellice, occurred in 2008), Liguria (Cinque Terre, occurred in 2011) and Sicily (Maugeri and Motta, 2011). The rapid kinematics characterizing the post-failure behavior of these phenomena implies that the setup of an EWS may not rely on the analysis of the short-lived paroxysmal stage (Fig. 2).

An exception is made for EWS implemented along some roads or railways, where the probability that the sliding mass detaching from a slope and directly impacting vehicles is small, while the probability of vehicles crashing against previously fallen mass obstructing the road is much higher. In such cases, the alarm might be sounded due to the danger posed by fallen masses. Hence, the alarm itself could be based on promptly observing the occurrence of slope instabilities by monitoring displacements and inhibiting road access in the case of recorded movements exceeding some threshold (Mannara et al., 2009).

If the exposed goods are instead likely to be directly impacted by the sliding mass, the triggering of the instability must be predicted in advance. The time span required to reduce exposure, typically a few hours, suggests that the prediction should be based on monitoring and interpretation of triggering precursors, carried out during the predisposing stage.

The phenomena at hand typically involve the mobilization of shallow covers rarely exceeding $2 \mathrm{~m}$ in thickness, induced by rainfall infiltration and related suction drop. Further physical variables governing the phenomenon are effect variables describing soil cover wetting (e.g., degree of saturation, water content, water storage).

The predictive model may be built on an empirical basis, whereas, for the referenced geographical context, historical data of rainfall and its effects are available. Alternatively, it is 


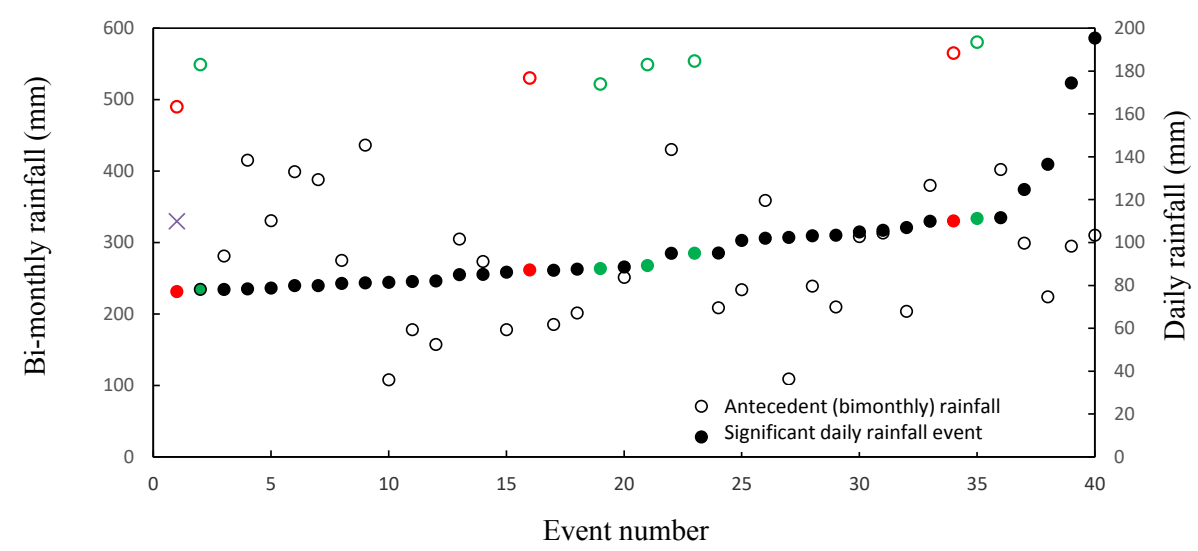

Figure 3. Daily and antecedent bimonthly rainfall recorded at the Nocera Inferiore site and corresponding to significant events (red circles are associated with landslide triggering and green circles with rainfall histories similar to those resulting in landslides).

possible to adopt physically based approaches that turn rainfall into effect variables related to slope stability conditions. Different levels of these effect variables (or of slope stability indices derived from them) may be chosen as the alert thresholds of the EWS. If the mathematical model of the slope has been properly simplified, it may be possible to operate "online" by performing model simulations in few minutes.

Recent advances in field monitoring of effect variables, in particular soil suction and/or water content, offer an alternative approach to the interpretation of rainfall effects. Sensors like tensiometers, heat dissipation probes and time-domain reflectometer (TDR) probes could, in principle, directly deliver all the effect variables needed for the assessment of slope stability conditions. However, the spatial variability of soil properties likely makes reliance on only field monitoring of effect variables unreliable. Field data are in fact always affected by local issues, and so they are poorly representative of the whole monitored area, unless an extremely rich network of sensors is installed, which in most cases is unfeasible. Hence, field monitoring should be deployed to supplement, rather than replace, the estimation of effect variables by means of a more or less simplified estimation of rainfall effects.

The following application examples refer to single slopes, with a size of a few hectares, located in the Lattari Mountains (Campania, southern Italy) and in the basin of Stura di Lanzo (Piedmont, northern Italy).

As already pointed out in the Introduction, the choice of presenting examples that refer to slope scale does not imply that the proposed classifications and procedures are limited to this case. The scale of the system does not intrinsically relate to model features but rather to the spatial resolution of the available input data, which affects the entire structure of the EWS. In the following examples, the choice of the slope scale is indeed made to show how, when high-resolution data are available, the adopted models and procedures for their calibration could be different and, in principle, applicable to any scale.

\subsection{Empirical approach based on rainfall records}

The example herein reported refers to the chain of Lattari Mountains and, in particular, to an area spreading between the towns of Pagani and Nocera Inferiore (Campania, southern Italy). An intensely fractured calcareous bedrock covered by silty volcanic soils characterizes the geology of the site. Volcanic covers have formed due to pyroclastic air-fall deposits generated by eruptions, mainly those of the volcanic complex of Somma-Vesuvius, that have occurred over the last 40000 years. Several rainfall-induced flow-like landslides have affected these covers over centuries. Numerous phenomena also occurred in the recent past (Table 1), usually triggered along slopes with an inclination angle between 30 and $40^{\circ}$.

A pluviometer installed in 1950, around $3 \mathrm{~km}$ from the downslope area, has provided a daily rainfall series for over 50 years (Pagano et al., 2010). During this period, three significant flow-like landslides occurred in 1960, 1972 and 1997 (Table 1). Daily rainfall heights triggering the three phenomena were 87,77 and $110 \mathrm{~mm}$, respectively. Figure 3 shows all the observed daily rainfall heights larger than the minimum value followed by a landslide $\left(h_{\mathrm{dL}}=77 \mathrm{~mm}\right.$; $h_{\mathrm{dL}}=$ minimum daily rainfall associated with a landslide), plotted in ascending order. It should be noted that the condition $h_{\mathrm{ds}}>h_{\mathrm{dL}}\left(h_{\mathrm{ds}}=\right.$ significant daily rainfall, with "significant" intended as exceeding $h_{\mathrm{dL}}$ ) was met 39 times, but only twice was a landslide actually triggered. This low correspondence between daily rainfall and landslides is due to the existence of additional influencing factors related to the conditions of the soil cover at the onset of triggering rainfall, which are neglected if only daily rainfall height is considered. Antecedent precipitation, in particular, is supposed to play a crucial role, as it determines the amount of water stored in the 
Table 1. Major flow-like landslides triggered since 1950 in the Lattari Mountains ( $H$ is the difference in elevation between the main crown and the tip of the accumulation zone; $L$ is the projection on the horizontal plane of the distance between the crown and the tip; $V$ is the volume of the landslide body) (modified from de Riso et al., 2007).

\begin{tabular}{llrrrr}
\hline Location & Town & Date (yyyy.mm.dd) & $H(\mathrm{~m})$ & $L(\mathrm{~m})$ & $V\left(\mathrm{~m}^{3}\right)$ \\
\hline San Pantaleone & Pagani & 1960.12 .08 & & & \\
Scrajo & Vico Equense & 1966.11 .23 & 220 & 300 & 10000 \\
Monte Pendolo & Gragnano & 1971.01 .02 & 205 & 375 & 7500 \\
San Pantaleone & Pagani & 1972.03 .06 & 90 & 180 & 5000 \\
San Pantaleone & Pagani & 1997.01 .10 & 135 & 240 & 4500 \\
Pozzano & Castellammare di Stabia & 1997.01 .10 & 440 & 750 & 40000 \\
Monte Pendolo & Gragnano & 1997.01 .10 & 125 & 210 & 4500 \\
Monte Pendolo & Pimonte & 1997.01 .10 & 125 & 135 & 4300 \\
Corsara & Corbara & 1997.01 .10 & 160 & 135 & 750 \\
Ospedaletto & 1997.01 .10 & 250 & 450 & 10000 \\
Sant'Egidio del Monte Albino & Ospedaletto & 1997.01 .10 & 215 & 500 & 10000 \\
Molina di Vietri & Sant'Egidio & 1998.05 .05 & 570 & 1700 & 9000 \\
Sant'Egidio del Monte Albino & Vietri sul Mare & 2005.03 .04 & 295 & 530 & 33000 \\
\hline
\end{tabular}

cover and lowering soil suction significantly, before the crucial suction drop induced by the triggering rainfall.

The effects of antecedent precipitations may be taken into account by assuming that, besides the rainfall directly triggering the event (usually identified with rainfall fallen during the last day), they also play an important role in establishing the predisposing conditions for the triggering of a landslide. The duration, $x$, of the antecedent period may be chosen as the one minimizing the number of events $\left(h_{\mathrm{ds}}, h_{x}\right)$ characterized by $h_{x}$, similar to the antecedent precipitation, $h_{x \mathrm{~L}}$, accumulated before the three observed landslides. The minimization yielded $x=2$ months. This corresponds to $h_{2 \mathrm{~mL}}$ values for all three landslides of about $500 \mathrm{~mm}$. Over the reference period only five rainfall histories $\left(h_{\mathrm{ds}}, h_{2 \mathrm{~m}}\right)$ were similar to the three $\left(h_{\mathrm{dL}}, h_{2 \mathrm{~mL}}\right)$ which were followed by a landslide. If this double threshold criterion had been virtually implemented as the early warning criterion in the considered area, it would have produced five false alarms over 50 years.

\subsection{Stochastic approach}

Few examples of real-time predictions of the probability of triggering of rainfall-induced landslides in a small area (i.e., a slope or a small catchment) can be found in the literature (e.g., Sirangelo and Versace, 1996; Sirangelo and Braca, 2004; Schmidt et al., 2008; Greco et al., 2013; Capparelli et al., 2013; Terranova et al., 2015; Manconi and Giordan, 2016; Ozturk et al., 2016). This is due to the intrinsic difficulty of finding historical data sets of rainstorms and corresponding landslides occurring in a small area, with enough data to allow reliable estimation of the probability of landslide triggering during extreme (and thus rare) rainfall events. Usually, only a few landslides occur at a site during an observation period of typically some decades, so that probabilistic landslide initiation thresholds are mostly defined at regional scale, so as to have a rich data set of observed landslides (e.g., Terlien, 1998; Guzzetti et al., 2007; 2008; Jakob et al., 2012; Ponziani et al., 2012; Segoni et al., 2015; Iadanza et al., 2016). The use of physically based models of infiltration and slope stability can help in the prediction of slope response under conditions different from those actually encountered during the observation period, thus allowing the definition of site-specific landslide initiation thresholds (e.g., Arnone et al., 2011; Ruiz-Villanueva et al., 2011; Tarolli et al., 2011; Papa et al., 2013; Peres and Cancelliere, 2014; Posner and Georgakakos, 2015; Greco and Bogaard, 2016), which can be useful for carrying out stochastic predictions. However, the application of such physically based approaches in operational EWS is difficult due to the computational burden involved, which makes carrying out the calculations required for landslide probability assessment difficult in real time. Consequently, empirical models of the relationship between rainfall and slope stability are still preferred for early warning purposes (Sirangelo and Braca, 2004; Greco et al., 2013; Manconi and Giordan, 2016; Ozturk et al., 2016).

An example of setting up an early warning predictive model to take into account the uncertainty of the prediction has been developed by coupling a stochastic predictive model of rainfall (Giorgio and Greco, 2009) with the empirical model FLaIR (Sirangelo and Versace, 1996), which yields predictions of the triggering time for rainfall-induced landslides. The same coupling approach may be used with other recently proposed empirical models, such as GA-SAKe (Terranova et al., 2015).

The FlaIR model associates landslide triggering conditions with values of a mobility function $Y(t)$, obtained by a convolution integral of the rainfall history $R(t)$ with a suitable transfer function $\psi(t)$, which allows us to model a wide variety of geomorphological contexts, taking into account 
predisposing conditions generated by antecedent rainfall (Iiritano et al., 1998; Sirangelo et al., 2003).

Both the choice of the transfer function and calibration of its parameters are carried out based on the historical rainfall data records in such a way that the $Y(t)$ function may be as a suitable proxy of slope stability conditions. In particular, parameters are calibrated so that peaks of $Y(t)$ correspond to historical landslides, so as to identify a threshold $Y_{\mathrm{cr}}$ that, if exceeded, indicates landslide occurrence.

The FLaIR model is currently implemented as a predictive model in EWS with different thresholds of attention, alert and alarm, corresponding to a progressive approach of $Y(t)$ to the $Y_{\mathrm{cr}}$ threshold. As an example, for the case of Sarno (pyroclastic slopes in southern Italy) the three mentioned thresholds were suggested at values of $0.4,0.6$ and $0.8 Y_{\mathrm{cr}}$, respectively (Sirangelo and Braca, 2004).

The coupling with a stochastic predictive model of rainfall allows us to adopt the FLaIR model as a predictor of the probability of occurrence of future landslides (Capparelli et al., 2013). In fact, the convolution integral may be separated into two parts: one deterministic and the other random. The first integral computes the convolution of the rainfall history $R_{\text {obs }}(t)$ until the time at which the prediction is carried out. The second integral computes the convolution of the rainfall history $R_{\text {pre }}(t)$ predicted for the future time interval $t_{\text {pre }}$, the upper bound of which represents the lead time of the prediction:

$$
\begin{aligned}
Y(t) & =Y_{\mathrm{det}}+Y_{\mathrm{pre}}=\int_{-\infty}^{t-t_{\mathrm{pre}}} \Psi(t-\tau) R_{\mathrm{obs}}(\tau) \mathrm{d} \tau \\
& +\int_{t-t_{\mathrm{pre}}}^{t} \Psi(t-\tau) R_{\mathrm{pre}}(\tau) d \tau .
\end{aligned}
$$

The prediction of $Y_{\text {pre }}$ is carried out by evaluating the probability conditioned to the trend of the rainfall observed before prediction. To this aim, the model DRIP (Disaggregated Rectangular Intensity Pulse) is adopted (Heneker et al., 2001). It defines, through an alternating renewal process, the observed alternation of rainfall and dry periods. This process guarantees the stochastic independence of a rainfall event from the duration of the immediately preceding dry period as well as from the duration and the total rainfall height of the previous rainstorm. This allows us to carry out the conditioned prediction $Y_{\text {pre }}$ by taking into account only the rainfall history observed during the current event, when the prediction is being carried out.

The prediction $Y_{\text {pre }}$ is carried out by a nonparametric approach by selecting only the $N_{i}$ rainfall events within the historical data set that meet the following two conditions: (1) their duration was equal to or longer than the observed part of the current rainstorm; or, (2) along a time interval as long as the lead time ( $\left.t_{\text {pre }}\right)$ before the prediction, the mobility function increased proportionally to that of the last observed $t_{\text {pre }}$ interval of the current rainfall event.

The rainfall events selected by following this procedure allow us to compute the expected value of $Y_{\text {pre }}$ and the probability that, at the end of the interval $t_{\text {pre }}$, the condition $Y>Y^{*}$ occurs, whatever $Y^{*}$ may be. Hence, once alert and alarm thresholds of the mobility function are defined, the sensitivity of the EWS can be adjusted by setting up the probability of threshold exceedance at which the relevant messages are launched (activation probability), so as to obtain the best trade-off between false and missing alarms (Greco et al., 2013). Low values of the activation probabilities result in a high number of alerts and alarms and may lead to false activations of the system (false alerts/alarms). Conversely, a less sensitive system unavoidably increases the number of erroneous non-activations of the system (missing alerts/alarms).

Setting the most suitable values of the activation probabilities is an important and crucial feature in the setting of an effective EWS. As already specified, the system sensitivity has to take into account all consequences relating to false and missing alarms. For the alert level, it is usually better to set a high sensitivity, since actions determined by alert activations usually do not imply high costs or a significant involvement of the served community. The same, however, cannot be stated for the alarm level, as the procedures resulting from alarm spreading usually accrue high costs and discomfort for the community. As an example, evacuation of people involves stopping all activities and interruption of all infrastructures and services of public utility.

The described approach has been applied to the slope of Pessinetto, $40 \mathrm{~km}$ northeast of Turin. The slope, oriented towards the southwest, with inclination angle between 30 and $35^{\circ}$, is part of the watershed of the river Stura di Lanzo. It is comprised of an intensively fractured metamorphic bedrock covered by a clayey silt. Six debris flows of different magnitude occurred there, within an area of about $1 \mathrm{~km}^{2}$, from November 1962 to October 2000. The thickness of mobilized soils ranged between 1.5 and $2.0 \mathrm{~m}$, with soil volumes between few hundreds and tens of thousands of cubic meters.

For the calibration of the stochastic model and the alert system, the pluviometer data recorded in Lanzo, located $6.5 \mathrm{~km}$ east of the slope, were available. In particular, the calibration has been carried out by interpreting the hourly rainfall heights recorded between 1 January 1956 and 10 September 1991, during which four of the six recorded landslides occurred. The subsequent data, from 11 September 1991 to 15 June 2004, have been adopted to validate the predictive model and the performance of an EWS based on its predictions.

The critical value for the mobility function, estimated over the calibration period, was $Y_{\mathrm{cr}}=168.4 \mathrm{~mm}$.

The minimum duration of a dry period between two rainfall events has been set to $10 \mathrm{~h}$. By assuming only rainfall events exceeding $5 \mathrm{~mm}$ to be significant for early warning purposes, a series of 1102 rainfall events that meet the re- 

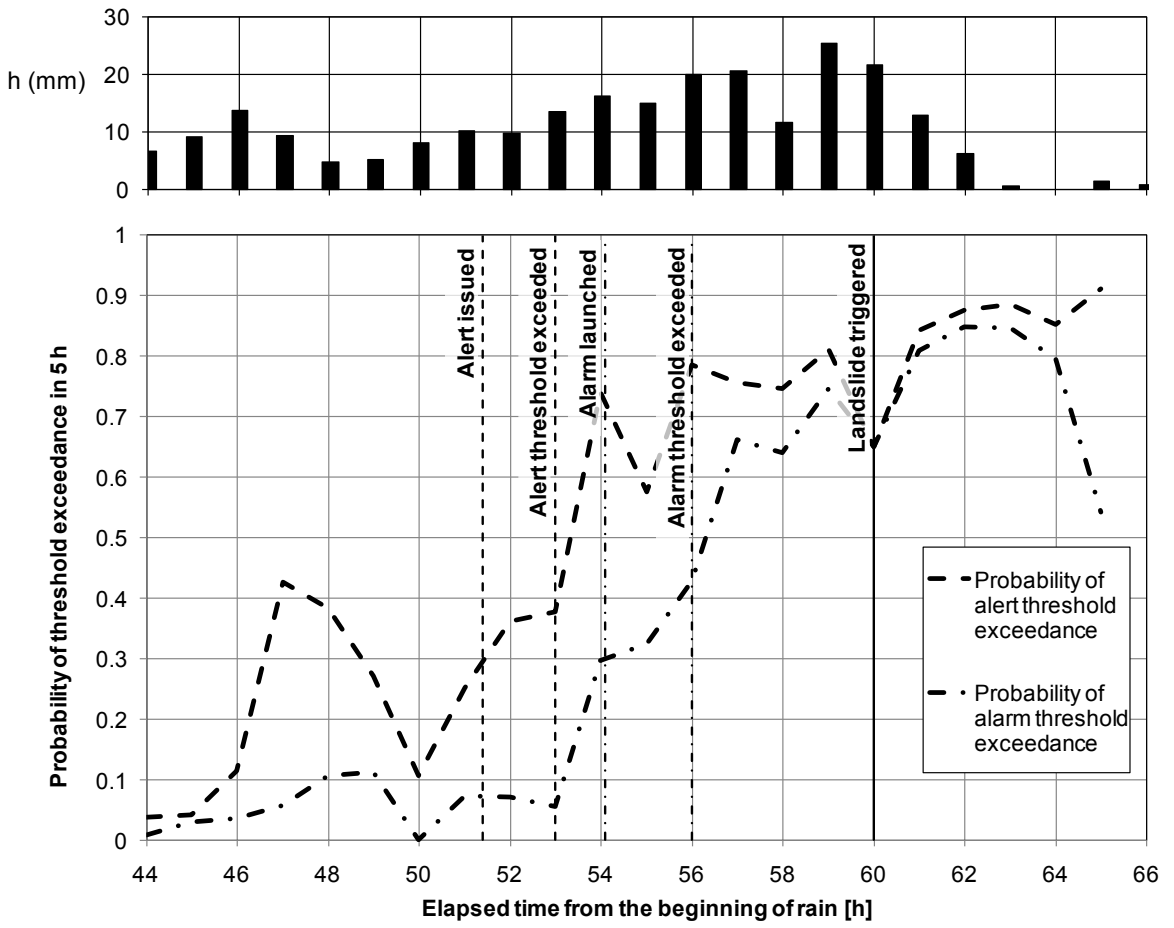

Figure 4. Stochastic approach to early warning: probability of exceeding alert and alarm thresholds of the mobility function at the slope of Pessinetto, predicted in real time (the upper panel reports the observed hyetograph) during the storm of 22 September 1993, when an earth flow occurred $60 \mathrm{~h}$ after the beginning of the rain.

quirements in terms of stochastic independency was selected within the calibration period. These selected events were characterized by durations between 1 and $182 \mathrm{~h}$ and rainfall heights between 5 and $615 \mathrm{~mm}$ (Greco et al., 2013). The validation period of the EWS included 456 rain events selected as for the calibration period.

The EWS has been implemented through the definition of two different operational levels: an alert level and an alarm level. The alert triggers as soon as the mobility function is predicted to approach the value of $Y_{\mathrm{a}}=0.75 Y_{\mathrm{cr}}$ with a probability higher than a predefined threshold $P_{1}$. The alarm is issued when the probability that $Y$ exceeds the critical value $Y_{\text {cr }}$ is higher than a second threshold $P_{2}$. The two thresholds are two examples of possible choices of warning thresholds. As shown hereinafter, for a given choice of warning thresholds, the sensitivity of the EWS depends both on the chosen probability thresholds. Predictions are updated with an hourly frequency and refer to a lead time interval from 1 to $6 \mathrm{~h}$ later than the prediction time.

Two examples of the potentiality of the predictions of the probability of exceeding the two defined thresholds are given for two rainfall events occurred during the validation period, both followed by landslides. In particular, the reported predictions were carried out with lead times of up to $5 \mathrm{~h}$.

The first event occurred between 22 and 25 September 1993, and $Y_{\mathrm{a}}$ and $Y_{\mathrm{cr}}$ were overtaken 54 and $58 \mathrm{~h}$ after the beginning of the rain, respectively. A landslide was triggered after $60 \mathrm{~h}$. In the second example, a rainfall event occurred between the 12 and 15 October 2000; $Y_{\mathrm{a}}$ was passed $39 \mathrm{~h}$ after the beginning of the rainstorm, $Y_{\mathrm{cr}}$ after $45 \mathrm{~h}$, and the landslide occurred after $46 \mathrm{~h}$.

The effectiveness of the stochastic approach for early warning is shown in Figs. 4 and 5. The graphs give the probability of exceeding the alert and alarm thresholds in the following $5 \mathrm{~h}$, predicted in real time. During the two considered rainfall events, the system predicted high values of the probability of exceeding both thresholds several hours in advance. In particular, assuming the activation probabilities $P_{1}=P_{2}=0.3$, in both cases (25 September 1993, Fig. 4; 14 October 2000, Fig. 5) the alert would have been issued about $9 \mathrm{~h}$ before the landslide, while the alarm would already have been launched $6 \mathrm{~h}$ earlier than the triggering time.

Hence, for the chosen values of $Y_{\mathrm{a}}$ and $Y_{\mathrm{cr}}$, by properly setting $P_{1}$ and $P_{2}$, the EWS would have been capable of issuing, in both cases, the alert and alarm messages several hours before the actual landslide triggering. Tables 2 and 3 show the influence of different choices for $P_{1}$ and $P_{2}$ on the performance of the EWS, evaluated in terms of total numbers of missing and false alerts and alarms during the entire validation period. It looks clear that, once the alert and alarm thresholds $Y_{\mathrm{a}}$ and $Y_{\mathrm{cr}}$ are defined, the sensitivity of the EWS depends on the chosen activation probability: higher probabilities correspond to larger numbers of missing alarms and smaller numbers of false alarms. 


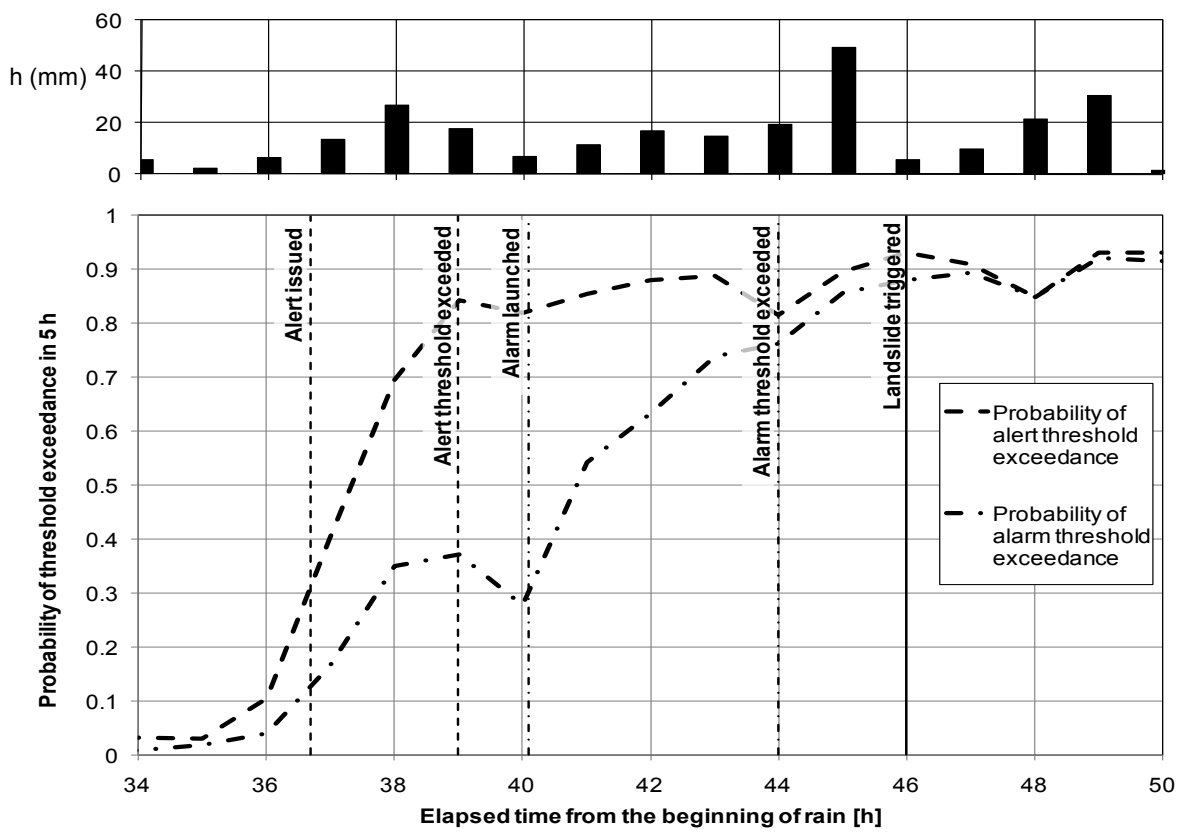

Figure 5. Stochastic approach to early warning: probability of exceeding alert and alarm thresholds of the mobility function at the slope of Pessinetto, predicted in real time (the upper panel reports the observed hyetograph) during the storm of 12.10.2000, when an earth flow occurred $46 \mathrm{~h}$ after the beginning of the rain.

Table 2. Stochastic approach to early warning: numbers of launched $\left(N_{1 \mathrm{~L}}\right)$, false $\left(N_{1 \mathrm{~F}}\right)$ and missing $\left(N_{1 \mathrm{M}}\right)$ alerts at the slope of Pessinetto for three different lead times $t_{\text {pre }}$ and three different choices of the probability of alert activation $P_{1}$. For each lead time, the system carried out 964 predictions between 11 September 1991 and 15 June 2004 (validation period).

\begin{tabular}{lrrr|rrr|rrr}
\hline$d_{\text {pre }}(\mathrm{h})$ & \multicolumn{3}{c|}{$P_{1}=0.2$} & \multicolumn{3}{c|}{$P_{1}=0.25$} & \multicolumn{3}{c}{$P_{1}=0.3$} \\
\cline { 2 - 9 } & $N_{1 \mathrm{~L}}$ & $N_{1 \mathrm{~F}}$ & $N_{1 \mathrm{M}}$ & $N_{1 \mathrm{~L}}$ & $N_{1 \mathrm{~F}}$ & $N_{1 \mathrm{M}}$ & $N_{1 \mathrm{~L}}$ & $N_{1 \mathrm{~F}}$ & $N_{1 \mathrm{M}}$ \\
\hline 2 & 23 & 7 & 2 & 19 & 3 & 2 & 18 & 2 & 2 \\
4 & 27 & 11 & 3 & 22 & 7 & 4 & 21 & 6 & 4 \\
6 & 31 & 12 & 3 & 25 & 7 & 4 & 22 & 5 & 5 \\
\hline
\end{tabular}

The optimal choice of $P_{1}$ and $P_{2}$ should be identified by comparing the costs derived from false and missing alerts and alarms, with the benefits of the true alarms. As already pointed out in the previous sections, such a cost-benefit analysis is of course particular to the considered case.

The capability of issuing the alert some hours earlier than the triggering time is a non-trivial feature of the system when it is implemented to mitigate risks from phenomena characterized by a very rapid evolution, such as debris flows, other types of fast landslides and flash floods. In these cases, effective measures to prevent damages and victims may be successfully implemented only if the alarm is issued sufficiently earlier than the triggering time of the phenomenon.

\subsection{Physically based approach}

In the town of Nocera Inferiore, a rain gauge, installed in 1997, recorded hourly rainfall $500 \mathrm{~m}$ far from the slope where, on 4 March 2005, a large landslide was triggered (Fig. 6). The slope had an inclination angle of $40^{\circ}$ and was covered with a $2 \mathrm{~m}$ thick layer of silty volcanic soils. Rainfall records are adopted in this example to validate a physically based approach (Pagano et al., 2010) suitable to take into account a number of known influencing factors (e.g., triggering event, antecedent precipitation, instantaneous rainfall intensity, evolution of potential infiltration) (Pagano et al., 2008; Rianna et al., 2014a).

In modeling the problem, only factors considered of minor importance were neglected, according to Pagano et al. (2010). In particular, a one-dimensional infiltration problem through an unsaturated rigid medium was set through Richards' equations, solved by the finite element code SEEP/W (GEO-SLOPE, 2004).

Hourly rainfall records were adopted to quantify boundary fluxes at the uppermost boundary, while at the lowermost boundary two different limit boundary conditions were as- 
Table 3. Stochastic approach to early warning: numbers of launched $\left(N_{2 \mathrm{~L}}\right)$, false $\left(N_{2 \mathrm{~F}}\right)$ and missing $\left(N_{2 \mathrm{M}}\right)$ alarms at the slope of Pessinetto for three different lead times $t_{\text {pre }}$ and three different choices of the probability of alarm activation $P_{2}$. For each lead time, the system carried out 964 predictions between 11 September 1991 and 15 June 2004 (validation period).

\begin{tabular}{lrrr|rrr|rrr}
\hline$d_{\text {pre }}(\mathrm{h})$ & \multicolumn{3}{c|}{$P_{2}=0.2$} & \multicolumn{3}{c|}{$P_{2}=0.25$} & \multicolumn{3}{c}{$P_{2}=0.3$} \\
\cline { 2 - 10 } & $N_{2 \mathrm{~L}}$ & $N_{2 \mathrm{~F}}$ & $N_{2 \mathrm{M}}$ & $N_{2 \mathrm{~L}}$ & $N_{2 \mathrm{~F}}$ & $N_{2 \mathrm{M}}$ & $N_{2 \mathrm{~L}}$ & $N_{2 \mathrm{~F}}$ & $N_{2 \mathrm{M}}$ \\
\hline 2 & 16 & 4 & 0 & 14 & 2 & 0 & 11 & 1 & 2 \\
4 & 22 & 10 & 0 & 17 & 5 & 0 & 15 & 4 & 1 \\
6 & 29 & 16 & 1 & 20 & 7 & 1 & 13 & 4 & 5 \\
\hline
\end{tabular}

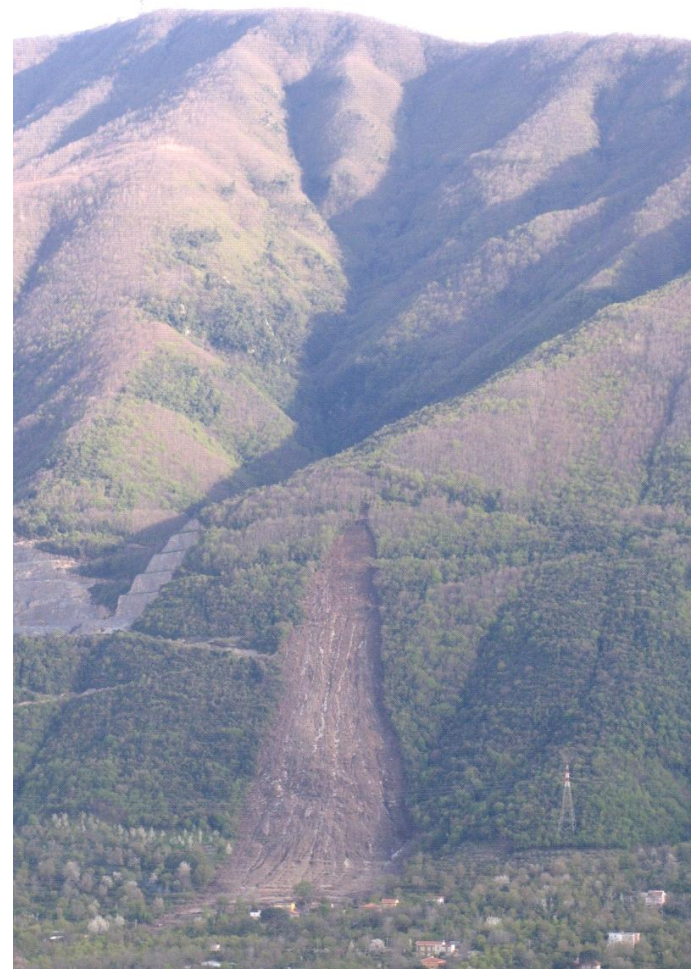

Figure 6. The Nocera Inferiore 2005 landslide area (Pagano et al., 2010, modified).

sumed (Reder et al., 2017) to account for the possible effects exerted by the fractured bedrock on the silty volcanic cover: a seepage surface condition, which simulates the capillary barrier effect under the hypothesis that fractures are empty, and a flux regulated by the unit gradient, which instead approaches the case of fractures filled with the same material as that constituting the cover. The hydraulic properties of the soil, i.e., water retention curve and hydraulic conductivity function, were obtained by means of laboratory tests (Nicotera and Papa, 2007) as well as by coupled measurements of soil matric suction (Jet Fill Tensiometer) and volumetric water content (TDR) carried out in a lysimeter (Rianna et al., 2014b).
Results yielded by the analyses (Reder et al., 2017) in terms of suction evolution refer to the hydrological year 2004-2005 (Fig. 7), which includes the landslide event. They clearly show how the predictions indicate a singularity at the triggering time, consisting of a drop of suction throughout the cover below $3 \mathrm{kPa}$ for both boundary condition types assumed at the bottom. Analyses conducted for the whole historical series of recorded rainfall, covering a time interval of 10 years including the landslide (Pagano et al., 2010), indicate that the same singularity is yielded by the prediction only once more. Hence, if this singularity (suction below $3 \mathrm{kPa}$ throughout the cover) had been adopted as an alarm criterion, the number of false alarms would have been significantly low. Furthermore, the short time required to update the prediction (few minutes) is consistent with the requirement of promptness of an EWS and allows us to carry out "inline" predictions.

\section{Conclusions}

After preliminary analysis of the reasons a community may adopt an EWS in place of structural approaches to mitigate risks associated with natural hazards, this paper identifies the key elements of an EWS, which make it effective in accomplishing the task of continuously checking the safety of a system. In particular, the work highlights the importance of the accuracy of the prediction of the future evolution of the system, which is the feature allowing the minimization of false and missing alarms. Then, the definition of three evolutionary stages of natural hazards is proposed, so as to set rational criteria to identify the time at which the prediction should be carried out within an EWS. In fact, depending on the characteristics of the hazardous phenomenon and on the time required for the prediction, the chosen stage should allow prompt action aimed at reducing exposure of people and goods.

Two further classification criteria are also adopted throughout this paper: the well-known distinction between empirical and physically based models and the distinction between online and offline predictions, never adopted in the field of water-related natural hazards. 

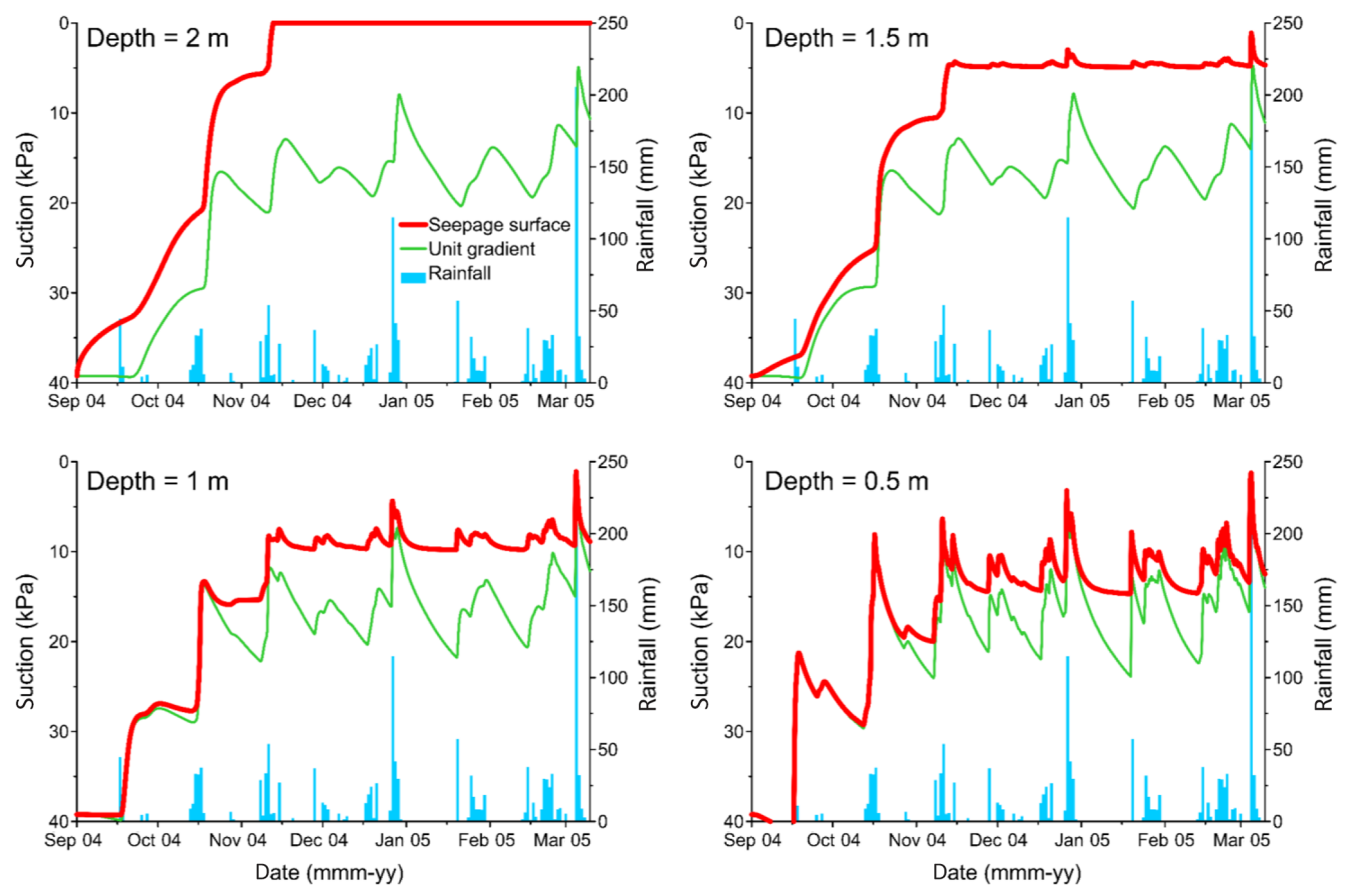

Figure 7. Prediction of suction evolution over the hydrological year of the Nocera Inferiore 2005 landslide at four different depths and for two different hydraulic conditions at the lowermost boundary (Reder et al., 2017, modified).

The practical application of the proposed evolutionary framing requires detailed physical knowledge of how the phenomenon develops over time and of the variables which can be used as a proxy of its evolution. This novel framework for the setup of EWS attempts to bring some order to their design procedures and is introduced with reference to various kinds of natural hazards, as in principle it is suitable to general application. Nonetheless, this paper is mainly focused on water-related natural hazards and particularly landslides, for which some application examples are given.

With reference to two different landslide phenomena, namely flow-like landslides and debris flows, both characterized by rapid evolution, this paper describes examples of applications of the proposed framework. First, the considered natural hazards are analyzed in terms of their possible evolutionary stages. Then, the most suitable stage for implementing the prediction is identified, along with cause and effect variables suitable to characterizing its evolution and assessing system safety conditions. The presented examples show how either empirical or physically based models may be adopted and how prediction uncertainty can be considered in setting up the sensitivity of an EWS.

The proposed frame and examples of application show how to design and set up an effective EWS (i.e., choosing the predictive model, the prediction time, the alert and alarm thresholds and their sensitivity, the mitigation actions allowed by the obtained lead time of prediction), and an indepth analysis of the physical characteristics of the hazardous phenomenon is mandatory.
Data availability. The data used in this research can be made available on demand. Please contact the authors for requests.

Competing interests. The authors declare that they have no conflict of interest.

Special issue statement. This article is part of the special issue "Landslide early warning systems: monitoring systems, rainfall thresholds, warning models, performance evaluation and risk perception". It is not associated with a conference.

Acknowledgements. The authors wish to thank the Ministero dell'Istruzione dell'Universitá e della Ricerca Scientifica (MIUR), which partly funded this work through the PRIN 2015 project titled "Innovative Monitoring and Design Strategies for Sustainable Landslide Risk Mitigation".

Edited by: Stefano Luigi Gariano

Reviewed by: two anonymous referees

\section{References}

Alfieri, L., Salamon, P., Pappenberger, F., Wetterhall, F., and Thielen, J.: Operational early warning systems for waterrelated hazards in Europe, Environ. Sci. Policy, 21, 35-49, https://doi.org/10.1016/j.envsci.2012.01.008, 2012. 
Alfieri, L. and Thielen, J.: A European precipitation index for extreme rain-storm and flash flood early warning, Meteorol. Appl., 22, 3-13, https://doi.org/10.1002/met.1328, 2015.

Arnone, E., Noto, L. V., Lepore, C., and Bras, R. L.: Physicallybased and distributed approach to analyze rainfall-triggered landslides at watershed scale, Geomorphology, 133, 121-131, https://doi.org/10.1016/j.geomorph.2011.03.019, 2011.

Bakkehoi, S.: Snow avalanche prediction using a probabilistic method, Avalanche Formation, Movement and Effects, Proceedings of the Davos Symposium, September 1986, IAHS Publ., $162,1986$.

Basher, R.: Global early warning systems for natural hazards: systematic and people centred, Philos. T. R. Soc. A, 364, $2167-$ 2182, https://doi.org/10.1098/rsta.2006.1819, 2006.

Baum, R. L. and Godt, J. W.: Early warning of rainfall-induced shallow landslides and debris flows in the USA, Landslides, 7, 259272, https://doi.org/10.1007/s10346-009-0177-0, 2010.

Bogaard, T. A. and Greco, R.: Landslide hydrology: from hydrology to pore pressure, WIREs Water, 3, 439-459, https://doi.org/10.1002/wat2.1126, 2015.

Calcaterra, D., De Riso, R., Evangelista, A., Nicotera, M. V., Santo, A., and Scotto di Santolo, A.: Slope instabilities in the pyroclastic deposits of the Phlegraean district and the carbonate Apennine (Campania, Italy), Proceedings of an International Workshop on Occurrence and Mechanisms of Flows in Natural Slopes and Earthfills held in Sorrento, Italy, 14-16 May 2003, 61-75, 2004.

Calvello, M. and Piciullo, L.: Assessing the performance of regional landslide early warning models: the EDuMaP method, Nat. Hazards Earth Syst. Sci., 16, 103-122, https://doi.org/10.5194/nhess16-103-2016, 2016.

Capparelli, G., Giorgio, M., and Greco, R.: Shallow Landslides Risk Mitigation by Early Warning: The Sarno Case, in: Landslide Science and Practice, edited by: Margottini, C., Canuti, P., and Sassa, K., Springer-Verlag, Berlin, 6, 767-772, https://doi.org/10.1007/978-3-642-31319-6_98, 2013.

Capparelli, G. and Tiranti, D.: Application of the MoniFLaIR early warning system for rainfall-induced landslides in Piedmont region (Italy), Landslides, 7, 401-410, https://doi.org/10.1007/s10346-009-0189-9, 2010.

Capparelli, G. and Versace, P.: FLaIR and SUSHI: two mathematical models for early warning of landslides induced by rainfall, Landslides, 8, 67-79, https://doi.org/10.1007/s10346-010-02286, 2011.

Cascini, L. and Ferlisi, S.: Occurrence and consequences of flowslides: a case study, Proceedings of an International Conference on Fast Slope Movements - Prediction and Prevention for Risk Mitigation held in Napoli, 11-13 May 2003, 1, 85-92, 2003.

Chleborad, A. F., Baum, R. L., and Godt, J. W.: A prototype system for forecasting landslides in the Seattle, Washington, area, in: Engineering geology and landslides of the Seattle, Washington, area, edited by: Baum, R. L., Godt, J. W., and Highland, L. M., Geological Society of America Reviews in Engineering Geology, Geological Society of America, Boulder, XX, 103-120, https://doi.org/10.1130/2008.4020(06), 2008.

Cranston, M. D. and Tavendale, A. C. W.: Advances in operational flood forecasting in Scotland, P. I. Civil Eng.-Wat. M., 165, 6987, https://doi.org/10.1680/wama.2012.165.2.79, 2012. de Riso, R., Budetta, P., Calcaterra, D., and Santo, A.: Riflessioni sul comportamento delle colate rapide non incanalate della Campania, alla luce delle conoscenze pregresse, Proc. National Conf. on La Mitigazione del Rischio da Colate di Fango, Napoli, May, 2-3, 2005, 81-92, 2007.

de Saint-Aubin, C., Garandeau, L., Janet, B., and Javelle, P.: A new French flash flood warning service, in: E3S Web of Conferences, edited by: Samuels, P., Klijn, F., and Lang, M., 3rd European Conference on Flood Risk Management, FLOODrisk 2016, Lyon, France, 17-21 October 2016, EDP Sciences, Les Ulis, 7, 18-24, https://doi.org/10.1051/e3sconf/20160718024, 2016.

Eichenberger, J., Ferrari, A., and Laloui, L.: Early warning thresholds for partially saturated slopes in volcanic ashes, Comput. Geotech., 49, 79-89, https://doi.org/10.1016/j.compgeo.2012.11.002, 2013.

GEO-SLOPE: SEEP/W for finite element seepage analysis,GEOSLOPE International, Calgary, 2004.

Giorgio, M. and Greco, R.: Rainfall height stochastic modelling as a support tool for floods and flowslides early warning, Water Engineering for a Sustainable Environment, Proceedings of XXXIII IAHR Congress, Vancouver, International Association of Hydraulic Engineering \& Research, August 2009, 6812-6819, 2009.

Greco, R. and Bogaard, T. A.: The influence of non-linear hydraulic behavior of slope soil covers on rainfall intensity-duration thresholds, in: Landslides and Engineered Slopes. Experience, Theory and Practice, edited by: Aversa, S., Cascini, L., Picarelli, L., and Scavia, C., 2, 1021-1025, Taylor and Francis, 2016.

Greco, R., Giorgio, M., Capparelli, G., and Versace, P.: Early warning of rainfall-induced landslides based on empirical mobility function predictor, Eng. Geol., 153, 68-79, https://doi.org/10.1016/j.enggeo.2012.11.009, 2013.

Guzzetti, F., Peruccacci, S., Rossi, M., and Stark, C. P.: Rainfall thresholds for the initiation of landslides in central and southern Europe, Meteorol. Atmos. Phys., 98, 239-267, https://doi.org/10.1007/s00703-007-0262-7, 2007.

Guzzetti, F., Peruccacci, S., Rossi, M., and Stark, C. P.: The rainfall intensity-duration control of shallow landslides and debris flows: an update, Landslides, 5, 3-17, https://doi.org/10.1007/s10346007-0112-1, 2008.

Heneker, T. M., Lambert, M. F., and Kuczera, G.: A point rainfall model for risk-based design, J. Hydrol., 247, 54-71, https://doi.org/10.1016/S0022-1694(01)00361-4, 2001.

Iadanza, C., Trigila, A., and Napolitano, F.: Identification and characterization of rainfall events responsible for triggering of debris flows and shallow landslides, J. Hydrol., 541, 230-245, https://doi.org/10.1016/j.jhydrol.2016.01.018, 2016.

Iiritano, G., Versace, P., and Sirangelo, B.: Real-time estimation of hazard for landslides triggered by rainfall, Environ. Geol., 35, 175-183, https://doi.org/10.1007/s002540050303, 1998.

Intrieri, E., Gigli, G., Mugnai, F., Fanti, R., and Casagli, N.: Design and implementation of a landslide early warning system, Eng. Geol., 147-148, https://doi.org/10.1016/j.enggeo.2012.07.017, 2012.

Intrieri, E., Gigli, G., Casagli, N., and Nadim, F.: Brief communication "Landslide Early Warning System: toolbox and general concepts", Nat. Hazards Earth Syst. Sci., 13, 85-90, https://doi.org/10.5194/nhess-13-85-2013, 2013. 
Jakob, M., Owen, T., and Simpson, T.: A regional real-time debris-flow warning system for the District of North Vancouver, Canada, Landslides, 9, 165-178, https://doi.org/10.1007/s10346011-0282-8, 2012.

Keefer, D. K., Wilson, R. C., Mark, R. K., Brabb, E. E., Brown, W. M., Ellen, S. D., Harp, E. L., Wieczorek, G. F., Alger, C. S., and Zatkin, R. S.: Real-time landslide warning during heavy rainfall, Science, 238, 921-925, https://doi.org/10.1126/science.238.4829.921, 1987.

Liu, X., Liu, Y., Li, L., and Ren, Y.: Disaster monitoring and early-warning system for snow avalanche along Tianshan highway, IEEE International Geoscience and Remote Sensing Symposium, IGARSS 2009, Cape Town, South Africa, 12-17 July 2009, IEEE Geoscience and Remote Sensing Society, 2, 1163411637, https://doi.org/10.1109/IGARSS.2009.5418166, 2009.

Ma, H. and Chi, F.: Major Technologies for Safe Construction of High Earth-Rockfill Dams, Engineering, 2, 498-509, https://doi.org/10.1016/J.ENG.2016.04.001, 2016.

Manconi, A. and Giordan, D.: Landslide failure forecast in nearreal-time, Geomatics, Natural Hazards and Risk, 7, 639-648, https://doi.org/10.1080/19475705.2014.942388, 2016.

Mannara, G., Sarnataro, A., Sposito, P., Piccolo, G., Ciancia, N., and Infante, S.: Rete di sensori accelerometrici MEMS per il monitoraggio in continuo di rilievi franosi in ambito ferroviario, SEF09 Sicurezza ed Esercizio Ferroviario I Convegno Nazionale, Roma 20 marzo 2009, 2009.

Martelloni, G., Segoni, S., Fanti, R., and Catani, F.: Rainfall thresholds for the forecasting of landslide occurrence at regional scale, Landslides, 9, 485-495, https://doi.org/10.1007/s10346011-0308-2, 2012.

Maugeri, M. and Motta, E.: Slope Failure. Effects of Heavy Rainfalls on Slope Behavior: The October 1, 2009 Disaster of Messina (Italy), in: Geotechnics and Earthquake Geotechnics Towards Global Sustainability, Geotechnical, Geological, and Earthquake Engineering, edited by: Iai, S., Springer, Dordrecht, 15, 2011.

Michoud, C., Bazin, S., Blikra, L. H., Derron, M.-H., and Jaboyedoff, M.: Experiences from site-specific landslide early warning systems, Nat. Hazards Earth Syst. Sci., 13, 2659-2673, https://doi.org/10.5194/nhess-13-2659-2013, 2013.

Nicotera, M. and Papa, R.: Comportamento idraulico e meccanico della serie piroclastica di Monteforte Irpino, Progetto PETITOSA Monitoraggio Frane: Contributo alle Conoscenze sulla Franosità in Campania, 272-280, ARACNE, 2007.

Ortigao, B. and Justi, M. G.: Rio-Watch: the Rio de Janeiro landslide alarm system, Geotechnical News, 22, 28-31, 2004.

Ozturk, U., Tarakegn, Y. A., Longoni, L., Brambilla, D., Papini, M., and Jensen, J.: A simplified early-warning system for imminent landslide prediction based on failure index fragility curves developed through numerical analysis, Geomatics, Natural Hazards and Risk, 7, 1406-1425, https://doi.org/10.1080/19475705.2015.1058863, 2016.

Pagano, L. and Sica, S.: Earthquake Early Warning for Earth Dams: Concepts and Objectives, Nat. Hazards, 66, 303-318, https://doi.org/10.1007/s11069-012-0486-9, 2013.

Pagano, L., Zingariello, M. C., and Vinale, F.: A large physical model to simulate flowslides in pyroclastic soils, Proc. First European Conf. on Unsaturated Soils: Advances in GeoEngineering, Durham, 205-213, 2008.
Pagano, L., Picarelli, L., Rianna, G., and Urciuoli, G.: A simple numerical procedure for timely prediction of precipitation-induced landslides in unsaturated pyroclastic soils, Landslides, 7, 273289, https://doi.org/10.1007/s10346-010-0216-x, 2010.

Papa, M. N., Medina, V., Ciervo, F., and Bateman, A.: Derivation of critical rainfall thresholds for shallow landslides as a tool for debris flow early warning systems, Hydrol. Earth Syst. Sci., 17, 4095-4107, https://doi.org/10.5194/hess-17-4095-2013, 2013.

Peres, D. J. and Cancelliere, A.: Derivation and evaluation of landslide-triggering thresholds by a Monte Carlo approach, Hydrol. Earth Syst. Sci., 18, 4913-4931, https://doi.org/10.5194/hess-18-4913-2014, 2014.

Piciullo, L., Gariano, S. L., Melillo, M., Brunetti, M. T., Peruccacci, S., Guzzetti, F., and Calvello, M.: Definition and performance of a threshold-based regional early warning model for rainfall-induced landslides, Landslides, 14, 995-1008, https://doi.org/10.1007/s10346-016-0750-2, 2017.

Ponziani, F., Pandolfo, C., Stelluti, M., Berni, N., Brocca, L., and Moramarco, T.: Assessment of rainfall thresholds and soil moisture modeling for operational hydrogeological risk prevention in the Umbria region (central Italy), Landslides, 9, 229-237, https://doi.org/10.1007/s10346-011-0287-3, 2012.

Posner, A. J. and Georgakakos, K. P.: Soil moisture and precipitation thresholds for real-time landslide prediction in El Salvador, Landslides, 12, 1179-1196, https://doi.org/10.1007/s10346-0150618-x, 2015.

Pumo, D., Francipane, A., Lo Conti, F., Arnone, E., Bitonto, P., Viola, F., La Loggia, G., and Noto, L. V.: The SESAMO early warning system for rainfall-triggered landslides, J. Hydroinform., 18, 256-276, https://doi.org/10.2166/hydro.2015.060, 2016.

Rabuffetti, D. and Barbero, S.: Operational hydro-meteorological warning and real-time flood forecasting: the Piemonte Region case study, Hydrol. Earth Syst. Sci., 9, 457-466, https://doi.org/10.5194/hess-9-457-2005, 2005.

Reder, A., Pagano, L., Picarelli, L., and Rianna, G.: The role of the lowermost boundary conditions in the hydrological response of shallow sloping covers, Landslides 14, 3, 861-873, https://doi.org/10.1007/s10346-016-0753-z, 2017.

Rianna, G., Pagano, L., and Urciuoli, G.: Rainfall patterns triggering shallow flowslides in pyroclastic soils, Eng. Geol., 174, 2235, https://doi.org/10.1016/j.enggeo.2014.03.004, 2014a.

Rianna, G., Pagano, L., and Urciuoli, G.: Investigation of soilatmosphere interaction in pyroclastic soils, J. Hydrol., 510, 480492, https://doi.org/10.1016/j.jhydrol.2013.12.042, 2014b.

Ruiz-Villanueva, V., Bodoque, J. M., Díez-Herrero, A., and Calvo, C.: Triggering threshold precipitation and soil hydrological characteristics of shallow landslides in granitic landscapes, Geomorphology, 133, 178-189, https://doi.org/10.1016/j.geomorph.2011.05.018, 2011.

Santo, A., Di Crescenzo, G., Del Prete, S., and Di Iorio, L.: The Ischia island flash flood of November 2009 (Italy): Phenomenon analysis and flood hazard, Phys. Chem. Earth, 49, 317, https://doi.org/10.1016/j.pce.2011.12.004, 2012.

Schmidt, J., Turek, G., Clark, M. P., Uddstrom, M., and Dymond, J. R.: Probabilistic forecasting of shallow, rainfall-triggered landslides using real-time numerical weather predictions, Nat. Hazards Earth Syst. Sci., 8, 349-357, https://doi.org/10.5194/nhess8-349-2008, 2008. 
Segoni, S., Battistini, A., Rossi, G., Rosi, A., Lagomarsino, D., Catani, F., Moretti, S., and Casagli, N.: Technical Note: An operational landslide early warning system at regional scale based on space-time-variable rainfall thresholds, Nat. Hazards Earth Syst. Sci., 15, 853-861, https://doi.org/10.5194/nhess-15-8532015, 2015.

Segoni, S., Rossi, G., Rosi, A., and Catani, F.: Landslides triggered by rainfall: a semiautomated procedure to define consistent intensity-duration thresholds, Comput. Geosci., 63, 123131, https://doi.org/10.1016/j.cageo.2013.10.009, 2014.

Sirangelo, B. and Braca, G.: Identification of hazard conditions for mudflow occurrence by hydrological model. Application of FLaIR model to Sarno warning system, Eng. Geol., 73, 267-276, https://doi.org/10.1016/j.enggeo.2004.01.008, 2004.

Sirangelo, B. and Versace, P.: A real time forecasting model for landslides triggered by rainfall, Meccanica, 31, 73-85, https://doi.org/10.1007/BF00444156, 1996.

Sirangelo, B., Versace, P., and Capparelli, G.: Forwarning model for landslides triggered by rainfall based on the analysis of historical data file, in: Hydrology of the Mediterranean and Semiarid Regions, edited by: Servat, E., Najem, W., Leduc, C., and Shakeel, A., IAHS Publ., 278, 298-304, 2003.

Tarolli, P., Borga, M., Chang, K. T., and Chiang, S. H.: Modeling shallow landsliding susceptibility by incorporating heavy rainfall statistical properties, Geomorphology, 133, 199-211, https://doi.org/10.1016/j.geomorph.2011.02.033, 2011.

Terlien, M. T. J.: The determination of statistical and deterministic hydrological landslide-triggering thresholds, Environ. Geol., 35, 124-130, https://doi.org/10.1007/s002540050299, 1998.

Terranova, O. G., Gariano, S. L., Iaquinta, P., and Iovine, G. G. R.: GASAKe: forecasting landslide activations by a geneticalgorithms-based hydrological model, Geosci. Model Dev., 8, 1955-1978, https://doi.org/10.5194/gmd-8-1955-2015, 2015.
Tiranti, D., Cremonini, R., Marco, F., Gaeta, A. R., and Barbero, S.: The DEFENSE (Debris Flows triggered by stormsNowcasting SystEm): an early warning system for torrential processes by radar storm tracking using a Geographic Information System (GIS), Comput. Geosci., 70, 96-109, https://doi.org/10.1016/j.cageo.2014.05.004, 2014.

Tiranti, D. and Rabuffetti, D.: Estimation of rainfall thresholds triggering shallow landslides for an operational warning system implementation, Landslides, 7, 471-481, https://doi.org/10.1007/s10346-010-0198-8, 2010.

UN-ISDR (United Nations Inter-Agency Secretariat of theInternational Strategy for Disaster Reduction): Hyogo framework for action 2005-2015: building the resilience of nations and communities to disasters, World Conference on Disaster Reduction, Kobe, Japan, January 2005, available at: https://www.unisdr.org/2005/wcdr/intergover/official-doc/

L-docs/Hyogo-framework-for-action-english.pdf (last access: 6 December 2017), 2005.

UN-ISDR (United Nations Inter-Agency Secretariat of the International Strategy for Disaster Reduction): Global Survey of Early Warning Systems: an assessment of capacities, gaps and opportunities towards building a comprehensive global early warning system for all natural hazards available at: http://www.unisdr.org/2006/ppew/info-resources/ ewc3/Global-Survey-of-Early-Warning-Systems.pdf (last access: 6 December 2017), 2006.

Varnes, D. J.: Slope movement types and processes, in: Special Report 176, edited by: Schuster, R. L. and Krizek, R. J., Landslides, Analysis and Control, Transportation and Road Research Board, National Academy of Science, Washington DC, 11-33, 1978. 